\title{
The Effect of Cryotherapy at the Hoku Point on the Severity of Pain of Fistula Catheterization in Hemodialysis Patients
}

\author{
Naimeh Porramezani $^{1}(\mathbb{D})$, Zahra Imani Goghary ${ }^{* 2}(\mathbb{D})$, Maryam Firouzabadi $^{2}(\mathbb{D})$, Mohadeseh Balvardi $^{3}(D)$, \\ Fatemeh Irannejad-Parizi ${ }^{4}(D$
}

1. Dept. of Nursing and Midwifery, Sirjan School of Medical Sciences, Kerman University of Medical Sciences, Kerman, Iran

2. Dept. of Nursing and Midwifery, Sirjan School of Medical Sciences, Sirjan, Iran

3. Dept. of Biostatistics, Sirjan School of Medical Sciences, Sirjan, Iran

4. Dept. of Pediatric Nursing, School of Nursing and Midwifery, Shiraz University of Medical Sciences, Shiraz, Iran

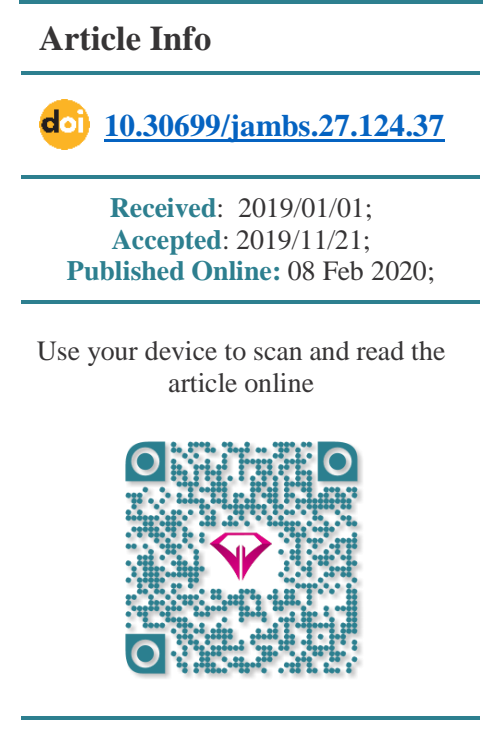

Corresponding Information: Zahra Imani Goghary, Dept. of Nursing and Midwifery, Sirjan School of Medical Sciences, Sirjan, Iran Email: Imanigoghary@yahoo.ca

\begin{abstract}
Background \& Objective: Pain is an unpleasant feeling that influences the quality of patients' life. Arteriovenous fistula catheterization pain can be reduced in hemodialysis patients with nonmedicinal and noninvasive methods of pain relief. This study aimed to investigate the efficacy of cryotherapy at the Hoku point on the severity of the pain of catheterization in hemodialysis patients.
\end{abstract}

Materials \& Methods: This quasi experimental study was conducted on 40 hemodialysis patients selected by census sampling method. In the first session, intensity of arterial and venous puncture pain, without applying any intervention, was recorded using the visual analogue scale (VAS). In the second and third sessions before catheterization, ice cubes were placed on the Hoku point for 10 minutes and the intensity of pain of arterial and venous fistula was immediately measured. Data were analyzed using SPSS 19 by independent t-test.

Results: The mean score of pain in the first session (arterial: $5.97 \pm 2.44$, venous: $6.00 \pm 2.62$ ) was compared with the mean score of pain in the second (arterial: $2.80 \pm 1.92$, venous: $2.72 \pm 2.09$ ) and third sessions (arterial: $2.42 \pm 1.72$, venous: $2.50 \pm 1.93$ ). The results of repeated measure analysis of variance showed that the mean score of pain significantly reduced in the second and third sessions compared to the first session $(P<0.05)$.

Conclusion: Cryotherapy at the Hoku point reduces the severity of pain of arteriovenous fistula catheterization and, thus, can be suggested as an effective noninvasive method for puncture pain relief in hemodialysis patients.

Keywords: Arteriovenous Fistula, Cryotherapy, Hemodialysis, Pain

Copyright $\odot$ 2019, This is an original open-access article distributed under the terms of the Creative Commons Attribution-noncommercial 4.0 International License which permits
copy and redistribution of the material just in noncommercial usages with proper citation.

\section{Introduction}

The National Kidney Foundation (NKF) has classified chronic kidney diseases (CKDs) in 5 stages. The fifth stage or the end-stage occurs when the kidneys cannot repulse materials of body metabolism and the glomerular filtration rate (GFR) falls below 15 $\mathrm{mL}$ every minute; thus, the patient would need renal replacement therapy (RRT) for the rest of his/her life (1). In recent years, CKD has become a life-threatening condition, influencing all aspects of patients' life, including social and financial status, family, and the society at large. In the last few years, CKD has attracted great attention, particularly in developed countries (2). Patients at the end-stage of kidney disease need renal replacement therapy (RRT), including dialysis and kidney transplant, for the rest of their life. Dialysis is the most common method employed on these patients, owing to the shortage of kidneys available for transplant (3).
There are myriads of methods to access the arteries for chronic hemodialysis, including arteriovenous fistula, artificial grafts, temporary catheters without cuff, and permanent catheters with cuff (1). There are certain problems with arteriovenous fistula; however, it is the best method because it reduces mortality, has a lower prevalence of complication, lesser need for subsequent therapeutic intervention and hospital admission, a longer life span compared to other methods, and lower costs (4).

On average, patients with end-stage renal disease who undergo hemodialysis are frequently faced with stress and pain of 300 fistula punctures per year. Pain reduction may help the patients accept and continue their treatment, improving their quality of life (5). Kyle and Ricci (2009) have categorized pain management strategies to pharmacological and nonpharmacological 
interventions. Nonpharmacological interventions include relaxation techniques, visual imagination, and cognitive behavioral strategies; biophysical interventions include acupressure, transcutaneous electrical nerve stimulation (TENS) combined with local heat or cold (6). Page and Taylor (2010) introduced pharmacological interventions such as applying local anesthetics before catheterization. EMLA (lidocaine 2.5\% and prilocaine 2.5\%) and Ametop (tetracaine 4\%) require at least 45 minutes before their effects can be observed; however, this delay in catheterization is unacceptable in emergency wards (7).

Cutaneous stimulation for pain relief has been well explained by the "Gate theory", which can be combined with acupressure to increase its effectiveness (8). Acupressure is a branch of Chinese traditional medicine that stimulates acupuncture points by using pressure and massaging to accelerate and control body functions. This effect is achieved through the stimulation of energy channels (meridian) that are vital energy transmission routes in the body (9). The large intestine meridian or the Hoku point is one of the acupressure points (5) with a 2 -way route (bilateral). It starts from the skin surface in the index finger, passes through the hand and arm, and goes to the end part of the shoulder. Then, the meridian leaves the skin surface to join the lower lung and transverse colon; next, it returns to the skin surface and the facial point next to the nostrils (8). The Hoku point, a large intestine meridian used in this study, is located between the first and the second bone of the palm, between the thumb and the index finger, and on the back of the hand (5). This point is easily reachable and stimulated by pressure, a needle, and extreme cold (10).

There are different strategies to alleviate pain in patients. Various studies have shown that using acupressure can relieve the pain intensity of dysmenorrhea $(9,11)$. Cryotherapy is another simple and effective method for relieving the pain of catheterization (12). On the other hand, studies have indicated that cold effectively blocks neural conduction in neural pathways (13). Fang et al. (2012) showed that cryotherapy with ice cubes in a plastic bag is effective on patients undergoing arthroscopic surgery (14). Also, Fareed et al. (2014) found that cryotherapy is one of the most effective skin techniques for the pain relief of patients (8). Some studies have shown that massaging the Hoku point with ice can reduce pain during venipuncture in children with thalassemia (10) and can also reduce pain intensity of arteriovenous fistula catheterization in children undergoing hemodialysis (15).

Studies have shown that skin stimulation, as an independent nursing action, can reduce pain at the Hoku point, which is used to relive the pain of the arms, hands, and shoulders. Also, cryotherapy at the Hoku point has been found to be effective for pain relief. Therefore, this study aimed to evaluate the effect of cryotherapy at the Hoku point on catheterization pain in adult patients undergoing hemodialysis.

\section{Materials and Methods}

This quasi-experimental study that was carried out in 2018, examined the effect of cryotherapy at the Hoku point on arteriovenous fistula catheterization pain of hemodialysis patients. Patients with chronic renal diseases admitted to the dialysis unit of Emam Reza hospital in Sirjan (the only hospital with a dialysis unit in Sirjan) were selected to participate in this study. The sample size was 40 based on accessible patients. Although 50 patients were undergoing hemodialysis, 2 had mental disorders and 8 were not willing to participate; therefore, only 40 patients met the inclusion criteria, all of whom were evaluated by the census method.

The inclusion criteria of the study were as follow: age above 18; both female and male patients; awareness of place, time, and person; having the ability to verbally communicate; receiving hemodialysis through arteriovenous fistula; and willingness to participate in the study. The exclusion criteria were as follow: need to try for catheterization more than once; fracture and inflammation at the massage point; host patient; peripheral vascular disease; Raynaud's syndrome; diabetes neuropathy according to medical documentaries; use of painkillers within 24 hours before hemodialysis; and numbness of the puncture site.

The scale of the study had 2 parts:

1) Demographic features: age, sex, education, duration of dialysis, number of dialysis session per week, history of underlying disease, duration of using fistula, and duration of disease.

2) The visual analogue scale (VAS) of pain, which is a graded ruler from zero to 10 , with zero representing the lower level of pain and 10 the higher level of pain. The VAS of pain is the easiest way to evaluate pain that can be easily understood by the patient (16).

The study was approved by Kerman University of Medical Sciences with code of ethics IR.KMU.REC.1395.286. Before the study, the goals and the process of the study were explained to the patients and informed consent was obtained.

Data were collected in 3 steps:

First Session: The demographic characteristics were collected by the researcher through interviews. AVF was performed by a nurse who was responsible for catheterization procedure. The researcher asked the patient to score the intensity of needling pain immediately after the AVF puncture of arterial and venous fistula separately using Visual Analog Scale for Pain (VAS).

Second Session: Ten minutes before catheterization of the fistula, 2 ice cubes wrapped in latex gloves were 
placed on the back of the patient's other hand at the Hoku point (Figures $\underline{1}$ and 2 ). Then, the ice cubes were moved in circles with mild pressure for 10 minutes. Then, the nurse performed catheterization and the patient was supposed to score the pain immediately after AVF puncture of arterial and venous fistula separately using the VAS scale.

Third Session: The third session was done the same as the second session to ensure that every factor which could lead to fake results were controlled and the results were genuine.

Data were analyzed using SPSS 15 (SPSS Inc., Chicago, Illinois, USA). Descriptive statistics were used to describe the demographic characteristics and cryotherapy-related factors in Hoku point. Ultimately, the effect of cryotherapy in Hoku point on reducing the pain of catheterization in hemodialysis patients was checked using repeated measure analysis of variance.

\section{Results}

The mean age of the patients was $57.78 \pm 11.79$, and most of them were male $(65 \%)$; $95 \%$ were married; $62.5 \%$ were illiterate; only $10 \%$ had academic education, and others had a high school diploma education level or less. Most patients (70\%) received hemodialysis 3 times a week and others twice a week; duration of receiving hemodialysis was $32.38 \pm 24.21$ months and duration of disease in these patients was $62.78 \pm 58.3$.

The mean score of pain of puncturing arterial and venous fistula in all sessions was compared separately using independent t-test; however, no significant difference was found between them $(P>0.05)$ (Table 1).

Then, the effect of cryotherapy at the Hoku point on reducing the pain of arteriovenous fistula catheterization was investigated using repeated measure analysis of variance. The results revealed a significant difference between the mean of the pain score of catheterizations before cryotherapy and the pain of catheterization in the second and third sessions in arterial $(\mathrm{F} 1,37=77.95, P<0.001)$ and venous $(\mathrm{F} 1$, $43=83.16, P<0.001)$ fistula. However, no significant difference was observed between the pain score and gender in arterial $(P=0.31)$ and venous $(P=0.20)$ puncture.

The results of pairwise comparisons using repeated measure analysis of variance (Bonferroni post hoc test) showed a significant difference between the mean score of arterial fistula puncturing pain in the first and second sessions and in the first and third sessions. However, no significant difference was found between the mean score of the pain of catheterization in the second and third sessions in arterial and venous fistula (Table 2).

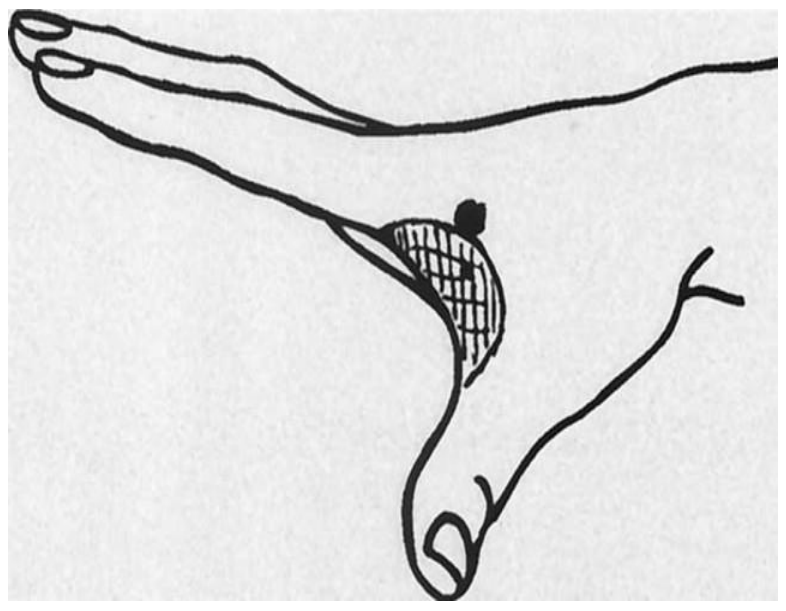

Figure 1. When the thumb and the index finger come together, they make a muscular peak at the Hoku point (17).

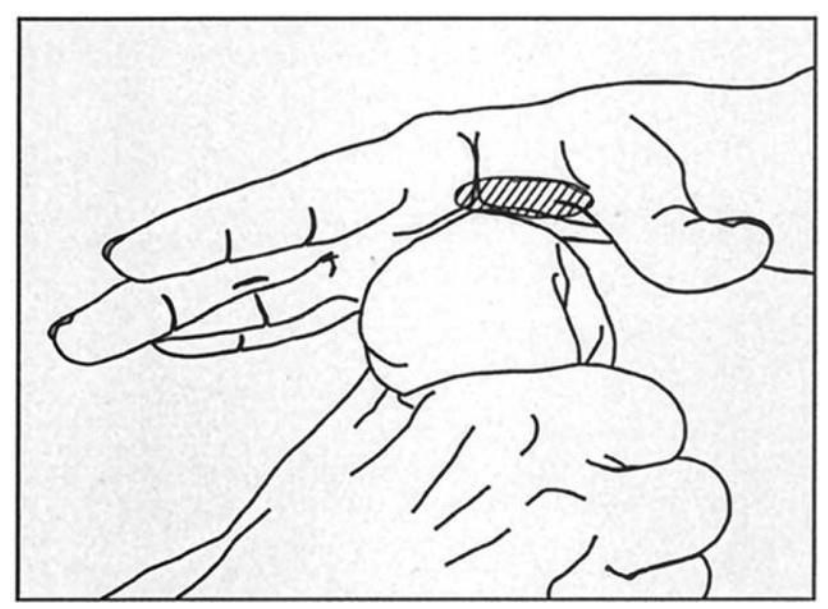

Figure 2. Cryotherapy at the Hoku point (17).

Table 1. Comparison of the mean score of pain between arterial and venous puncture in 3 separate sessions

\begin{tabular}{cccccccccc} 
& \multicolumn{3}{c}{$\begin{array}{c}\text { First session } \\
\text { Variabl }\end{array}$} & \multicolumn{3}{c}{ (without intervention) } & \multicolumn{2}{c}{$\begin{array}{c}\text { Second session } \\
\text { (with cryotherapy) }\end{array}$} \\
$\begin{array}{c}\text { e } \\
\text { Arterial } \\
\text { fistula }\end{array}$ & $\begin{array}{c}\text { Venous } \\
\text { fistula }\end{array}$ & P-value & $\begin{array}{c}\text { Arterial } \\
\text { fistula }\end{array}$ & $\begin{array}{c}\text { Venous } \\
\text { fistula }\end{array}$ & P-value & $\begin{array}{c}\text { Arterial } \\
\text { fistula }\end{array}$ & $\begin{array}{c}\text { Venous } \\
\text { fistula }\end{array}$ & P-value \\
$\begin{array}{c}\text { Mean } \\
\text { score of } \\
\text { pain }\end{array}$ & $5.97 \pm 2.44$ & $6.00 \pm 2.62$ & 0.819 & $2.80 \pm 1.92$ & $2.72 \pm 2.09$ & 0.965 & $2.42 \pm 172$ & $2.50 \pm 1.93$ & 0.965 \\
\hline
\end{tabular}


Table 2. Pairwise comparisons of the mean score of arterial and venous fistula puncturing pain by Bonferroni Post Hoc test

\begin{tabular}{|c|c|c|c|c|}
\hline Parameter & $\begin{array}{c}\text { First session } \\
\text { (without intervention) }\end{array}$ & $\begin{array}{l}\text { Second session } \\
\text { (with cryotherapy) }\end{array}$ & $\begin{array}{l}\text { Third session } \\
\text { (with cryotherapy) }\end{array}$ & P-value \\
\hline Arterial fistula & $5.97 \pm 2.44$ & $2.80 \pm 1.92$ & $2.42 \pm 1.72$ & $\begin{array}{l}\text { I-II: } 0.00 \\
\text { I -III: } 0.00 \\
\text { II-III: } 0.36\end{array}$ \\
\hline Venous fistula & $6.00 \pm 2.62$ & $2.72 \pm 2.09$ & $2.50 \pm 1.93$ & $\begin{array}{l}\text { I-II: } 0.00 \\
\text { I -III: } 0.00 \\
\text { II-III: } 0.23\end{array}$ \\
\hline
\end{tabular}

\section{Discussion}

Pain during puncturing of arteriovenous fistula is a common problem in hemodialysis patients, which affects patients' quality of life $(18,19)$. This study aimed to investigate the effect of cryotherapy at the Hoku point, as a nonpharmacological method, to reduce the pain of AVF in hemodialysis patients.

In the present study, the mean age of the patients was above 50 years, which was expected, as most of patients who suffer from chronic renal diseases are middle-aged. The patients were dialyzed for at least 2 years. However, the results of the statistical analysis did not show any significant relationship between catheterization pain and variables such as age, sex, education status, duration of dialysis, number of dialysis sessions, duration after AVF creation, and duration of the disease. Aghajanloo et al. (2016) found no significant relationship between pain score and age, duration of dialysis, and duration of AVF (5). Furthermore, Sabitha et al. (2008) found no significant relationship between the pain score with the duration of AVF and age. However, they remarked that women feel more pain than men (20). Figueiredo et al. (2008) indicated that the mean intensity of pain in women and men was different, but it was not significant (21). This little difference can be related to the pain threshold in females, which is lower than males due to sex hormones (22).

The results of this study indicated that applying cryotherapy at the Hoku point can reduce pain intensity of fistula puncture. Different studies have investigated the effect of cryotherapy at the Hoku point on reducing pain and provided useful results that are consistent with the results of the present study. For example, Pouraboli et al. (2015) showed that cryotherapy can be effective in reducing the pain of venipuncture in children with thalassemia (10). The first study that explored the effect of cryotherapy as a skin stimulation technique to reduce AVF puncture-related pain of dialysis patients was the work of Sabitha and colleagues (2008). They found that cryotherapy was effective in reducing the AVF puncture-related pain of dialysis patients (20). Furthermore, Hassan et al. (2012) performed a study on children undergoing hemodialysis and found the same result; they suggested cryotherapy as a routine care before dialysis (15).

Patients undergoing hemodialysis are concerned about catheterization pain. The feeling of pain is not specifically limited to children; adults also mentioned catheterization as an unpleasant experience (23). In a study, $30 \%$ of patients expressed strong pain, $58.5 \%$ mild pain, and only $11.5 \%$ expressed low catheterization pain (24). Pain related to needlepuncturing is problematic when a person requires subsequent punctures (25). Therefore, pain relief is important for adults as well.

Davtalab et al. (2016) studied the effect of massaging the Hoku point with ice to reduce the pain of AVF catheterization in adult patients. They found that cryotherapy is effective in reducing the pain of AVF catheterization, which is consistent with the present study (12). Also, Aghajanloo et al. (2016) confirmed the positive effect of the aforementioned technique in pain relief and suggested this method to nurses to reduce the pain of catheterization (5).

Considering the patients' rights and the pyramid of Maslow's needs, pain relief is one of the fundamental needs of human beings (12). Pharmacological and nonpharmacological methods are used for pain relief. However, nonpharmacological methods are preferred. Studies have shown that skin stimulation is a nursing independent intervention that results in pain relief (8). Cryotherapy is an effective skin stimulation technique. It is cost-effective, has low complication, and is easyto-use, and does not have complications like skin rush, skin erythema, and itches that are caused by local anesthetic drugs such as EMLA cream, lidocaine, and other drugs in the same category (7).

Since patients with kidney failure need frequent vascular access for dialysis, cryotherapy can be used as a nonpharmacological pain relief method with no complications in hemodialysis units. This method has been suggested to nurses in dialysis units for pain relief. It is also suggested that the pain relief effect of cryotherapy be compared with that of nonpharmacological interventions. One advantage of cryotherapy is that it can be performed by patients. 
Considering the shortage of nurses and their lack of time, hemodialysis patients can be trained to use this technique.

\section{Conclusion}

Cryotherapy at the Hoku point as an independent nursing intervention and uncomplicated pain relief method, can reduce the severity of pain of arteriovenous fistula catheterization, thus, it can be suggested as an effective noninvasive method for puncture pain relief in hospitalized patients especially those undergoing hemodialysis.

\section{Study Limitations}

Despite the fact that VAS is a standard scale, perceived pain varies between individuals and is of a subjective nature.

The sample size was small due to the small number of patients in Sirjan. Thus, future studies should be conducted with larger sample sizes.

\section{Acknowledgments}

We thank the staff of the dialysis unit of Emam Reza hospital, Mrs. Nadimi, and the nurses, Mrs. Gharaie and Mrs. Khan Aghaie, without whose efforts, this study would have not been performed. Also, our gratitude is extended to all the patients on hemodialysis at Emam Reza hospital of Sirjan who participated in this study.

\section{Conflict of Interest}

Authors declared no conflict of interests.

\section{References}

1. Hinkle JL, Cheever KH. Clinical Handbook for Brunner \& Suddarth's Textbook of Medical-surgical Nursing: Lippincott Williams \& Wilkins; 2013.

2. Shahgholian N, Tajdari S, Nasiri M. Body image in patients undergoing dialysis. Iran J Nurs Midwifery Res. 2015;10(3):s85-s90

3. Talebi M, Mokhtari Lakeh N, Rezasoltani P. Caregiver burden in caregivers of renal patients under hemodialysis. J Holistic Nurs Midwifery. 2016;26(2):59-68.

4. Beladi MSS, Hayati F, Neseri I, Zeraati AA. Comparison of temporary dialysis catheter and AV fistula use at the time of starting chronic hemodialysis among end-stage renal diseases patients.J Mashhad Univ Med Sci. 2011;24(2):75-79
5. Aghajanloo A, Ghafourifard M, Haririan H, Gheydari PS. Comparison of the effects of cryotherapy and placebo on reducing the pain of arteriovenous fistula cannulation among hemodialysis patients: A randomized control trial. J Nurs Midwifery Sci. 2016;3(1):59-65. [DOI:10.18869/acadpub.jnms.3.1.59]

6. Ricci SS, Kyle T. Maternity and pediatric nursing: Lippincott Williams \& Wilkins; 2009.

7. Page D, Taylor DM. Vapocoolant spray vs subcutaneous lidocaine injection for reducing the pain of intravenous cannulation: a randomized, controlled, clinical trial. British J Anaesthesia. 2010;105(4):51925. [DOI:10.1093/bja/aeq198]

8. Fareed APME, El-Hay AHA, El-Shikh AA. Cutaneous stimulation: Its effect on pain relieving among hemodialysis patients.J Educate Pract. 2014;5(1):9-20

9. Gharloghi S, Zahrani ST, Heshmat R, Akbarzade A. The effects of acupressure points in SP6 and SP8 on primary dysmenorrhea. Patient Prefer Adherence. 2012; 6: 137-42. doi: 10.2147/PPA.S27127. 2011;15(4).

10. Pouraboli B, Abazari F, Rostami M, Jahani Y. Comparison the effect of two methods of acupressure and massage with ice on Huko point on pain intensity during IV insertion in pediatrics with thalassemia. J Pediatr Nurs. 2015;2(2):20-7.

11. Rakhshekhorshid M, Foadoddini M, Saadatjoo SA. Comparison between the effects of applying massage and ice massage to SP6(SPLEEN6) point on severity and length of primary dysmenorrheal. J Birjand Univ Med Sci. 2013;20(1):11-9.

12. Davtalab E, Naji S, Shahidi S. Comparing the effects of valsalva maneuver and ice massage at Hoku point methods on pain intensity within the needle insertion to the arteriovenous fistula (AVF) for patients undergoing hemodialysis in the selected hospitals in Isfahan in 2015. Int J Med Res \& Helth Sci. 2016;5(5):101-7.

13. Afzali M, Ebadi A, Haj Amini Z. Study the effect of ice massage on labor pain in parturient women who reffered to allocated hospitals in Tehran city. Ebnesina. 2011;14(1):17-22.

14. Fang L, Hung CH, Wu SL, Fang SH, Stocker J. The effects of cryotherapy in relieving postarthroscopy pain. J Clin Nur. 2012;21(5-6):636-43. [DOI:10.1111/j.1365-2702.2010.03531.x]

15. Hassan A, Darwish MM, El-Samman GA, Fadel FI. The impact of cryotherapy on pain intensity at puncture sites of arteriovenous fistula among children undergoing hemodialysis. J Am Sci. 2012;8(12):1490500 .

16. Amin MR. Correlation between visual analogue scale and short form of McGill questionnaire in patients with chronic low back pain. Qom Univ Med Sci J. 2012;6(1).31-34

17. Waters BL, Raisler J. Ice massage for the reduction of labor pain. J Midwifery Womens Health. 2003;48(5):317-21. [DOI:10.1016/S15269523(03)00277-0] 
18. Golda M, Revathi D, Subhashini N, Mathew J, Indira A. Assess the effectiveness of cold application on pre procedure (AV fistula puncture) pain among hemodialysis patients in tertiary care hospital, Nellore. Int J Appli Res. 2016;2(6):660-64.

19. Borzou SR, Akbari S, Fallahinia G-H, Mahjub H. The effect of acupressure at the point of hugo on pain severity of needle insertion in arteriovenous fistulas in hemodialysis patients. Nephro-Urol Monthly. 2017 10 (1); e14252 [DOI:10.5812/numonthly.14252]

20. Sabitha P, Khakha D, Mahajan S, Gupta S, Agarwal M, Yadav S. Effect of cryotherapy on arteriovenous fistula puncture-related pain in hemodialysis patients. Indian J Nephrol. 2008;18(4):155. [DOI: 10.4103/0971-4065.45290]

21. Figueiredo AE, Viegas A, Monteiro M, Poli-deFigueiredo CE. Research into pain perception with arteriovenous fistula (avf) cannulation. J Renal Care. 2008;34(4):169-72. 6686.2008.00041.x] [DOI:10.1111/j.1755

\section{How to Cite This Article:}

Porramezani N, Imani Goghary Z, Firouzabadi M, Balvardi M, Irannejad-Parizi F. The Effect of Cryotherapy in the Hoku point on the Severity of Pain of Fistula Catheterization in Patients on Hemodialysis. J Adv Med Biomed Res. 2019; 27 (124) :37-42

\section{Download citation:}

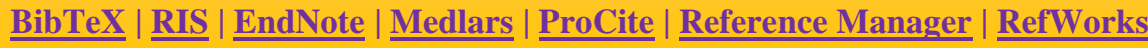

\section{Send citation to:}

(9) Mendelev 2 Zotero ORefForks RefWorks
22. Fillingim RB. Sex, gender, and pain. Principles of Gender-Specific Medicine (Third Edition): Elsevier; 2017. p. 481-96. [DOI:10.1016/B978-0-12-8035061.00038-3]

23. Griva K, Li ZH, Lai AY, Choong MC, Foo MWY. professionals on decision-making about dialysis modality-the good, the bad, and the misunderstandings. Perit Dial Int. 2013;33(3):280-9. [DOI:10.3747/pdi.2011.00308]

24. da Silva OM, Rigon E, Dalazen JVC, Bissoloti A, $\begin{array}{llll}\text { Open } & \text { J } & \text { Nurs. } & \text { 2016;6(12):1028. }\end{array}$ [DOI:10.4236/ojn.2016.612098]

25. Davison SN, Jhangri GS. Impact of pain and symptom burden on the health-related quality of life of hemodialysis patients. J Pain Symptom Manage. 2010;39(3):477-85. [DOI:10.1016/j.jpainsymman.2009.08.008] Perspectives of patients, families, and health care Rabelo-Silva ER. Pain during arteriovenous fistula cannulation in chronic renal patients on hemodialysis. 